\title{
O USO DO DOCUMENTÁRIO “DERRUBARAM O PINHEIRINHO" PARA O ESTUDO DE CONCEITOS DE GEOGRAFIA URBANA EM UMA TURMA DE PROEJA
}

\author{
Francisco Fernandes Ladeira \\ E-mail: ffernandesladeira@yahoo.com.br \\ Instituto Federal de Educação, Ciência e Tecnologia do Espírito Santo \\ DOI: 10.15628/rbept.2020.8711
}

Artigo submetido em jun/2019 e aceito em mar/2020

\begin{abstract}
RESUMO
Este trabalho apresenta os resultados obtidos em uma prática pedagógica realizada na disciplina de Geografia em que o documentário "Derrubaram o Pinheirinho" foi exibido e debatido com alunos de uma turma do PROEJA com o objetivo de estudar os conceitos de "especulação imobiliária", "gentrificação", "autoconstrução" e "segregação socioespacial. Após a exibição do vídeo, houve uma breve discussão em que docente e discentes apontaram as questões que mais Ihes chamaram a atenção em "Derrubaram o Pinheirinho" e, posteriormente, o professor apresentou uma atividade proposta sobre o documentário assistido. A partir da experiência didática aqui relatada também foi possível uma melhor compreensão por parte dos discentes sobre os conceitos anteriormente citados, fator que confirma a importância de se incorporar diferentes linguagens ao ensino de Geografia.
\end{abstract}

Palavras-Chave: documentário. Geografia. PROEJA. Conceitos.

\section{TTHE USE OF THE DOCUMENTARY "DERRUBARAM O PINHEIRINHO" FOR THE STUDY OF CONCEPTS OF URBAN GEOGRAPHY IN A PROEJA CLASS}

\begin{abstract}
This paper presents the results obtained in a pedagogical practice carried out in the Geography discipline in which the documentary "Derrubaram o Pinheirinho" was watched and debated with students from a group of the PROEJA with the objective of study the concepts of "real estate speculation", "gentrification", "self-construction" and "socio-spatial segregation". After the documentary was presented, there was a brief discussion in which the teacher and students pointed out the issues that most caught their attention in "Derrubaram o Pinheirinho" and, later, the teacher presented a proposed activity about the assisted documentaryFrom the didactic experience reported here, it was also possible to better understand the concepts previously mentioned, a factor that confirms the importance of incorporating different languages into the teaching of Geography.
\end{abstract}

Keywords: documentary; Geography. PROEJA. Concepts. 


\section{CONSIDERAÇÕES INICIAIS}

A incorporação de diferentes linguagens midiáticas (cinema, televisão, internet, jornais, documentários, etc.) às aulas de Geografia no ensino básico é uma prática pedagógica cada vez mais recorrente. Conforme apontam vários relatos de experiências didáticas (COSTA, 2009; KATUTA, 2009; MARQUES, 2017), após a introdução do material midiático no ambiente escolar, os alunos se sentem mais estimulados, o processo de ensinoaprendizagem tende a se tornar mais prazeroso e a apreensão dos conteúdos ministrados ocorre de maneira mais eficaz.

No entanto, é importante salientar que a utilização do material midiático em sala de aula precisa ir além da simples transmissão de informação; isto é, professores e alunos devem analisar reflexivamente uma determinada produção, questionar o seu conteúdo e identificar quais ideologias podem estar por trás de seu discurso.

De acordo com Ladeira e Leão (2018), também é fundamental que a incorporação do material midiático supere a posição de mera ilustração didática, e a reflexão de professor e alunos tenha como ponto de partida o conhecimento geográfico.

Para Costa (2009), a análise crítica de jornais impressos em sala de aula, conectando o conhecimento geográfico com acontecimentos atuais, contribui para que os alunos aprimorem suas capacidades interpretativas e compreendam melhor os processos de construção espacial da sociedade.

Seguindo essa linha de raciocínio, Katuta (2009) afirma que o uso de jornais no ambiente escolar pode auxiliar os alunos no entendimento da produção do espaço em múltiplas escalas, pois este veículo de comunicação registra, sob as mais variadas perspectivas, as geograficidades em nível local, regional e global.

Por sua vez, Marques (2017) descreve como a exibição e posterior discussão do filme iraniano "Filhos do Paraíso" em uma aula de Geografia foi importante para contrapor visões reducionistas, estereotipadas e preconceituosas que os alunos possuíam em relação à civilização islâmica, de maneira geral, e ao Irã, em particular.

Já Ladeira e Leão (2018) destacam que os documentários - produções artísticas não-ficcionais, que se caracterizam principalmente pelo compromisso de exploração da realidade - geralmente trazem visões diversificadas sobre variadas temáticas presentes na Geografia Escolar.

Sendo assim, o presente trabalho relata uma prática pedagógica, realizada na disciplina de Geografia, em que o documentário "Derrubaram o Pinheirinho" foi exibido e debatido com alunos de uma turma do Programa de Integração da Educação Profissional ao Ensino Médio (PROEJA) do Instituto Federal do Espírito Santo (IFES) com o objetivo de estudar os conceitos de "especulação imobiliária", "gentrificação", "autoconstrução" e "segregação socioespacial", que constituem elementos fundamentais na compreensão da produção do espaço urbano.

Para tanto, observamos as três aulas em que o documentário foi assistido e discutido e, posteriormente, relatamos as principais observações e conclusões feitas pelos alunos sobre as atividades propostas pelo professor, 
buscando relacioná-las com alguns dos referenciais bibliográficos que abordam a produção do espaço urbano e o funcionamento do maquinário midiático.

\section{2 “DERRUBARAM O PINHEIRINHO”}

O documentário "Derrubaram o Pinheirinho" narra a história dos moradores da ocupação denominada "Pinheirinho", localizada em um terreno no município São José dos Campos (SP) que faz parte da massa falida da empresa Selecta, de propriedade do megaespeculador libanês Naji Robert Nahas.

Em 1981, Nahas comprou o terreno de um empresário do ramo imobiliário pelo valor de 120 milhões de cruzeiros. No entanto, depois que Naji Nahas tornou-se dono do terreno, ele ficou abandonado, não sendo utilizado para qualquer finalidade agrícola, habitacional ou comercial, descumprindo assim a sua função social, de acordo com a Constituição Federal (BRASIL, 1988).

Segundo informações apresentadas pelo documentário, a única função do terreno para Naji Nahas foi utilizá-lo como garantia para conseguir dois empréstimos, ainda na década de 1980: o primeiro, de 1 bilhão de cruzeiros, pelo Banco do Brasil; e o segundo, no valor de 10 milhões de dólares, junto a uma instituição bancária privada francesa (DERRUBARAM O PINHEIRINHO, 2013).

Percebe-se, nesse caso, a prática de "especulação imobiliária", que ocorre quando proprietários de terrenos baldios em áreas urbanas deixam estes espaços desocupados a espera de valorização. Uma das consequências da especulação imobiliária é a falta de moradias em locais mais bem localizados, fazendo com que as populações de mais baixa renda tenham que viver em regiões distantes do centro ou em favelas (impulsionando o crescimento horizontal citadino):

\footnotetext{
Enquanto porções do solo urbano parcial ou totalmente atendidas permanecem ociosas, contingentes cada vez maiores da população se instalam em áreas não servidas. [...] $O$ padrão periférico de crescimento decorre da existência de mecanismos econômicos que conferem ao solo urbano funções econômicas alheias à sua utilidade intrínseca enquanto bem natural e ao papel que deveria desempenhar na composição e na organização do espaço requerido para as atividades públicas ou privadas da população (BOLAFFI, 1979, p. 58).
}

Em 1989, a Selecta entrou em processo de falência, e todos os seus bens, incluindo o terreno onde futuramente se instalaria a comunidade do Pinheirinho, foram bloqueados para, posteriormente, serem leiloados com o objetivo de quitar dívidas, passando a integrar a chamada "massa falida" da empresa.

No entanto, o terreno não foi leiloado, permanecendo abandonado até que, em fevereiro 2004, foi ocupado por duzentas famílias do Movimento dos 
Trabalhadores Sem Teto (MTST) que fundaram a comunidade do Pinheirinho. Em reportagem de janeiro 2012, a TV Vanguarda (afiliada da Rede Globo no Vale do Paraíba), produziu o seguinte resumo sobre o Pinheirinho:

As primeiras famílias chegaram em fevereiro de 2004. Elas vieram de uma outra ocupação num bairro vizinho, o Dom Pedro I. Invadiram um conjunto habitacional da CDHU [Companhia de Desenvolvimento Habitacional e Urbano], mas foram expulsas. Esse foi o primeiro confronto com a polícia. Os sem teto começaram então a montar os barracos de madeira no terreno onde hoje é o Pinheirinho.

Nota-se, no discurso acima reproduzido, uma nítida tentativa de representar negativamente a comunidade do Pinheirinho, através da menção aos confrontos entre moradores e a polícia e da utilização da palavra "invadiram", que possui uma forte carga semântica pejorativa, remetendo a ações às margens da lei.

Já a solução habitacional encontrada pelos moradores da comunidade do Pinheirinho está relacionada à ideia de "autoconstrução".

A autoconstrução, o mutirão, a auto-ajuda, a ajuda mútua são termos usados para designar um processo de trabalho calcado na cooperação entre as pessoas, na troca de favores, nos compromissos familiares, diferenciando-se portanto das relações capitalistas de compra e venda da força de trabalho. [...] Nos grandes centros industriais, ela [autoconstrução] ganha importância cada vez mais fundamental no que diz respeito à construção de casas destinadas à classe trabalhadora (MARICATO, 1979, p. 71).

Uma temática bastante presente ao longo do documentário foi a extrema negligência com o que os poderes judiciário, municipal, estadual e federal trataram as questões que envolviam o Pinheirinho, sendo que um dos fatores que impediram a regularização da comunidade foi a grande valorização econômica do terreno onde ela se localizava:

Logo no início da ocupação, em 2004, o valor do terreno era de aproximadamente 7 milhões de reais. [...] Quando a região passou a ser um polo industrial de alta tecnologia, o valor do terreno subiu absurdamente, passando de 100 milhões de reais. Isso atraiu a atenção de muitos empresários do ramo imobiliário interessados em construir galpões industriais na região (DERRUBARAM $\mathrm{O}$ PINHEIRINHO, 2013).

Isso significa que o terreno passou pelo processo de "gentrificação", que se refere às mudanças nas paisagens urbanas, aos usos e significados de zonas antigas e/ou populares das cidades que apresentam sinais de degradação física, passando a atrair moradores de rendas mais elevadas (GLASS, 1964; ALCÂNTARA, 2018). Em outros termos, trata-se do fenômeno que atinge uma região ou bairro pela alteração das dinâmicas da composição 
do local, tal como novos pontos comerciais ou construção de novos edifícios, valorizando a região e afetando, principalmente, a população de baixa renda local (GRANT, 2003; REID; ADELMAN, 2003).

Por fim, em 22 de janeiro de 2012, após diversas disputas judiciais, a Polícia Militar, cumprindo ordens da justiça do estado de São Paulo, realizou a reintegração de posse, expulsando, de maneira truculenta, todos os moradores do Pinheirinho.

Neste mesmo dia, "foram vistas cenas absurdas. Tratores derrubaram as casas, com os pertences dos moradores ainda lá dentro. Muitas saíram de casa apenas com a roupa do corpo" (DERRUBAM O PINHEIRINHO, 2013). Desse modo, podemos concluir que "o governo defendeu bastante o direito de propriedade da Selecta, mas ignorou completamente o direito de propriedade dos moradores, ao destruir seus móveis e outros pertences" (idem).

Posteriormente, a maioria dos ex-moradores da comunidade Pinheirinho foi para abrigos improvisados pela prefeitura são joseense em ginásios, igrejas e escolas; alguns passaram a morar em casas alugadas ou de parentes e outros, sem opções, ocuparam imóveis abandonados em áreas de risco, constituindo-se assim em típicos exemplos da chamada "segregação socioespacial", processo caracterizado por dois tipos distintos de uso habitacional do solo urbano: autossegregação e segregação induzida.

A autossegregação está relacionada às ações de certos grupos sociais que se distinguem pelo elevado poder de compra e de mobilidade residencial que se isolam ou se concentram em determinadas áreas como forma de reprodução de seu poder político e social (ROMERO et al., 2005).

Por outro lado, a segregação induzida (o caso dos ex-moradores do Pinheirinho) ocorre quando os indivíduos das classes baixas, sem recursos para residirem nas regiões mais valorizadas da cidade, passam a ocupar os piores terrenos do espaço urbano, como encostas de morros ou áreas próximas a leitos de rios.

Além do estudo de importantes conceitos em Geografia Urbana anteriormente citados, o documentário também nos permite refletir sobre 0 processo de "manipulação midiática", que, segundo Ladeira e Leão (2018, p. 35):

Ocorre [...] na produção e construção da notícia, com a seleção de assuntos considerados de interesse público, no tratamento dado a uma informação, ao fazer juízo de valores, na escolha das fontes a serem ouvidas, na ampliação de um fato, em estratégias discursivas, no repertório lexical e ao privilegiar um enquadramento da realidade em detrimento de outros pontos de vista possíveis.

No processo de desocupação do Pinheirinho, a violência desmedida utilizada pelos policiais militares contra os moradores da comunidade, por exemplo, não foi noticiada pelos principais grupos de comunicação brasileiros. Trata-se do chamado "Padrão de Ocultação" de manipulação 
midiática, que, de acordo com Abramo (2016), está relacionado à ausência e à presença de determinados fatos na produção da imprensa:

\begin{abstract}
A mídia, ao definir em sua pauta aquilo que entende que deve ser noticiado, oculta, intencionalmente, parte da realidade. [...] Tomada a decisão de que um fato "não é jornalístico", não há a menor chance de que o leitor tome conhecimento de sua existência, por meio da imprensa. O fato real foi eliminado da realidade, ele não existe. O fato real ausente deixa de ser real para se transformar em imaginário. $\mathrm{E} O$ fato presente na produção jornalística, real ou ficcional, passa a tomar o lugar do fato real, e a compor, assim, uma realidade diferente do real, artificial, criada pela imprensa (ABRAMO, 2016, p. 41).
\end{abstract}

Portanto, para se informar sobre o que realmente estava ocorrendo na comunidade Pinheirinho durante a desocupação do terreno, "era preciso ir a internet, em sites de notícias alternativos, em blogs e nas redes sociais. [...] As imagens mais terríveis do dia não foram vistas na Globo, SBT ou Record, mas sim no Youtube [...] filmadas pelos próprios moradores e outros cinegrafistas" (DERRUBARAM O PINHEIRINHO, 2013).

\title{
3 METODOLOGIA E DESENVOLVIMENTO
}

Esta investigação teve como referencial metodológico a pesquisa exploratória, a partir da perspectiva de um estudo de caso, isto é, na análise sistemática de uma determinada realidade e suas peculiaridades. Segundo Gil (1988), a pesquisa exploratória proporciona maior conhecimento para o pesquisador sobre um assunto específico, permitindo que ele possa compreender o cotidiano escolar como possibilidade de vivências únicas e impregnadas de sentido (GODOY, 1995; GIL, 1988). Desse modo, a opção pela realização de estudo de caso se deve pela possibilidade que essa perspectiva tem em retratar a realidade de forma complexa e profunda, levando em consideração o contexto em que os diferentes atores sociais se situam (LÜDKE; ANDRÉ, 2003, SCOPEL et al, 2012).

Nesse sentido, com o objetivo de dar voz os sujeitos-objetos que participaram deste trabalho, o que significa valorizar as reflexões discentes como aspectos fundamentais do processo de ensino-aprendizagem, optamos por citar algumas das falas mais emblemáticas dos alunos nas descrições dos resultados obtidos.

$O$ estudo de caso aqui relatado foi observado em três aulas da disciplina de Geografia, em uma turma de $2^{\circ}$ Período do Curso Técnico em Metalurgia Integrado ao Ensino Médio, do IFES, Campus Vitória, na modalidade PROEJA. A turma em questão contava, à época de nossa observação, com 28 alunos. Como se tratava de um curso noturno, a maior parte dos discentes pertencia à classe trabalhadora, principal público-alvo do PROEJA: 
As orientações oficiais para o PROEJA assinalam a defesa da necessidade de uma formação integral, que busque contribuir para a compreensão do mundo do trabalho e as múltiplas relações presentes nele. Pensada assim esta formação contribui para que os sujeitos sejam capazes de compreender e inserirem-se na realidade atuando de "forma ética e competente, técnica e politicamente, visando à transformação da sociedade em função dos interesses sociais e coletivos especialmente os da classe trabalhadora" (MEC, 2007) (PINTO; ZANARDINI, 2013).

De acordo com o professor de Geografia, a maioria dos alunos apresentava grandes dificuldades em compreender conceitos abstratos presentes nas aulas ministradas sobre urbanização como "especulação imobiliária", "gentrificação" e "segregação socioespacial". Diante dessa realidade, ele concluiu que, caso pudesse apresentar exemplos práticos sobre as temáticas estudadas em sala de aula, os alunos poderiam, enfim, ter uma melhor compreensão sobre o conteúdo didático. Desse modo, o docente resolveu incorporar à sua aula o documentário "Derrubaram o Pinheirinho", produção independente dirigida por Fabiano Amorim, lançada em 2013.

Devido a extensão do documentário "Derrubaram o Pinheirinho" (85 minutos), foram necessárias três aulas para que o mesmo fosse assistido e posteriormente comentado.

Terminada a exibição do vídeo, o professor perguntou aos alunos se eles gostaram do conteúdo apresentado. De maneira unânime, as respostas foram positivas, o que era esperado, pois, ao longo da exibição do documentário, já havíamos percebido o grande envolvimento dos alunos, sobretudo nas cenas de maior caráter emotivo, como as agressões policiais a idosos, o processo de demolição das casas da comunidade, os relatos de moradores que perderam todos os seus pertences e as passagens em que crianças brincavam em meios aos destroços das casas do Pinheirinho.

Também foi proposta uma atividade de análise sobre o documentário "Derrubaram o Pinheirinho", contendo as seguintes questões:

1) Qual era a situação do terreno mostrado no documentário antes de sua ocupação pelos moradores do Pinheirinho? Era utilizado para fins habitacionais, comerciais ou agrícolas? Quem era o seu proprietário?

2) Como a ocupação do Pinheirinho foi retratada pela grande mídia (Rede Globo, TV Bandeirantes, SBT e Rede Record)?

3) As cenas sobre o Pinheirinho mostradas no Youtube eram semelhantes às apresentadas na grande mídia? Justifique.

4) Como a ocupação Pinheirinho foi tratada pelos poderes públicos (judiciário, municipal, estadual e federal)?

5) Como foi o processo de desocupação do Pinheirinho?

6) O que aconteceu com os moradores do Pinheirinho após desocuparem o terreno onde moravam?

7) Relacione o documentário "Derrubaram o Pinheirinho" aos conceitos de "especulação imobiliária", "gentrificação", "autoconstrução" e "segregação socioespacial". 
8) Quais as suas conclusões sobre o documentário?

Como não houve tempo hábil para que os alunos terminassem a atividade, o professor solicitou que a mesma fosse entregue na aula seguinte.

\title{
4 RESULTADOS E DISCUSSOES
}

O rendimento apresentado pelos alunos em relações às questões da atividade proposta foi bastante satisfatório. De maneira geral, eles conseguiram identificar que as cenas mostradas no Youtube sobre 0 Pinheirinho eram muito diferentes das narrativas presentes na grande mídia, pois, segundo as suas respostas, as coberturas dos grandes grupos de comunicação sobre os acontecimentos que desencadearam na desocupação do Pinheirinho eram superficiais, tendenciosas e pouco esclarecedoras, conforme demonstram os exemplos a seguir:

\begin{abstract}
A mídia ocultava muitos fatos ocorridos na desocupação do Pinheirinho, já no youtube as filmagens foram expostas sem filtro, como realmente ocorreu.

No youtube estavam relatos reais e chocantes, de um ângulo que as mídias não mostram. Na grande mídia [havia] um relato supérfluo do que eles queriam que nós disséssemos (não a realidade como ela é).

No youtube mostravam as verdadeiras cenas e a triste realidade dos moradores, toda luta e sofrimento ali enfrentados. A mídia passava reportagens de poucos minutos, comparando moradores a bandidos. A mídia omite as informações do massacre no Pinheirinho. Coloca o local como ponto de drogas. Local onde só existe bandido, perante a mídia. Mas a realidade é totalmente diferente.
\end{abstract}

Nessas respostas, os discentes concluíram que a mídia tenta impor uma determinada visão de mundo aos receptores de suas mensagens. Já a última observação, em especial, faz referência a uma passagem do documentário que mostra uma reportagem da TV Vanguarda sobre o suposto uso de moradias da comunidade Pinheirinho para o tráfico de entorpecentes, funcionando como uma espécie de "crackolândia". De acordo com Ladeira e Leão (2018, p. 226):

A mídia procura aparentar imparcialidade, porém o repertório lexical por ela utilizada, a concessão de mais espaço a uma notícia em detrimento de outras, a maneira como é desenvolvida a cobertura de um acontecimento, a escolha do título de uma matéria e os critérios para o posicionamento de uma foto são exemplos de posturas que deixam transparecer posicionamentos ideológicos e eliminam a ideia de uma possível neutralidade da informação. Os 
grandes grupos de comunicação geralmente servem aos interesses de governos ou das empresas que os financiam.

Os discentes também perceberam a extrema negligência com o que os poderes judiciário, municipal, estadual e federal trataram as questões que envolviam a comunidade do Pinheirinho:

Foram jogando a responsabilidade um nas costas do outro, enquanto um queria resolver da melhor forma, o outro não queria. Não tiveram vontade de resolver.

O grupo que coordenava a cidade, os poderes públicos, não viam o Pinheirinho como uma cidade e sim como invasores, o que houve foi um abuso de poder contra os moradores. [...] A prefeitura de São José não olhou pelos moradores, nem o governo, tampouco a presidência petista. $O$ governo federal poderia ter comprado 0 terreno e regularizado a situação.

Minha conclusão é o que governo não quis regularizar a situação dessas famílias para economizar e acabou se prejudicando financeiramente e acabou com as famílias tendo as suas casas destruídas.

No fim da história, a prefeitura simplesmente teve que abrigar cada uma das famílias afetadas e ainda teve que fornecer um auxílio aluguel até que as casas ficassem prontas. Ou seja, gastou para tentar impedir que os moradores permanecessem ali e gastaram para abriga-los.

Nas duas últimas respostas, os alunos mencionam o fato de que a prefeitura do município de São José dos Campos, ao não chegar a uma solução para a situação dos moradores do Pinheirinho (optando por travar várias disputas judiciais) e, após a desocupação do terreno, ter que alojar os moradores em ginásios, igrejas e escolas, além de pagar aluguéis sociais às famílias, teve um gasto financeiro bem maior do que teria se estivesse regularizado a comunidade.

Ao apontar as suas conclusões sobre o documentário assistido durante as aulas de Geografia, um aluno mencionou as ações negativas do poder público e da mídia em relação aos moradores da comunidade do Pinheirinho.

A desocupação do Pinheirinho foi feita de uma maneira muito desrespeitosa com os moradores do local, visto que o terreno era abandonado. O abuso das autoridades destruindo casas com os pertences dentro, o uso de força desnecessária naquele ambiente e a não transparência da mídia com a população.

Outras observações apresentadas dizem respeito às desigualdades inerentes ao sistema capitalista e à concepção de que o poder financeiro é o principal regulador das relações sociais no Brasil: 
Minhas conclusões sobre o documentário são que, se você tiver dinheiro, poder e influência sobre algo ou alguém, você faz o que quiser. Documentário excelente, porém, repugnante realidade. É muito triste.

Resumindo, "Derrubaram o Pinheirinho" foi um documentário que retratou o abuso de poder dos empresários e poderes públicos em cima de um povo que não tinha recursos para se defender ou questionar, porque estavam sendo destituídos de um terreno desabitado, sem finalidade nenhuma, sem possibilidade nenhuma de trazer algum tipo de benefício a sociedade. [...] Houve grandes injustiças e a corda sempre arrebenta para o lado mais fraco. $O$ povo fica sem voz, sem defesa e vivendo a mercê de quem não se importa com nada, apenas com status, fama e poder.

Estas colocações nos fazem refletir sobre a urgência de se fomentar uma realidade socialmente mais justa, em que o "direito à cidade" esteja intrinsicamente relacionado à formação de uma nova configuração urbana, na qual predomine o valor de uso do espaço citadino - focado nas necessidades das pessoas, principalmente daquelas pertencentes às classes baixas - em detrimento de seu valor de troca - voltado, sobretudo, para o seu potencial mercadológico, ou seja, à sua capacidade de criar condições propícias para a reprodução do capital (LEFEBVRE, 1991).

Portanto, é importante compreender a produção do espaço não apenas sob o ponto de vista material, ou seja, em sua infraestrutura física; pois, mais do que moradias dignas para todos, o urbano deve ser pensado como local que possibilite aos seus moradores o pleno desenvolvimento de suas capacidades, habilidades e aspirações.

Sobre as relações entre o documentário "Derrubaram o Pinheirinho" e os conceitos de "especulação imobiliária", "gentrificação" e "segregação socioespacial", os alunos escreveram:

Naji Nahas esperou o terreno que foi ocupado pelos moradores do Pinheirinho ter valor para expulsar os moradores, depois de ter sofrido alteração no comércio e desenvolvimento local. Como eles não tinham pra onde ir, foram obrigados a morar em periferias.

No documentário Derrubaram o Pinheirinho o proprietário do terreno fez especulação imobiliária usando o seu terreno como penhora caso não pagasse seu empréstimo, pois ele sabia que o valor de seu terreno subiria com o passar do tempo. A segregação socioespacial é vista pelo fato de pessoas ter que invadir um terreno, isso pelo fato de os espaços na cidade custarem muito caro e alugueis e casas com preços não acessíveis para trabalhadores de baixa renda.

A área onde estava a ocupação do Pinheirinho estava sendo usada para especulação imobiliária por Naji Nahas para aumentar a valorização da área, causando a gentrificação da terra, por não cumprir com suas funções sociais de gerar moradia, agricultura ou indústria. Então, algumas pessoas, sem condições de ter a casa própria, ocuparam a terra, criando a ocupação Pinheirinho, o que gerou também uma segregação socioespacial por se tornar uma região pobre e de família de baixa renda. 
O Pinheirinho foi ocupado em um terreno de área privada, cujo proprietário era Naji Nahas. A propriedade ficou vazia desde a década de oitenta, à espera da valorização econômica (especulação imobiliária). A gentrificação notamos quando o bairro cresceu, onde houve abertura de mercados, escolas, etc., o que acabou, portanto, valorizando o terreno. A desocupação à força demonstra o conceito de "segregação socioespacial", isso ocorre, muitas vezes, quando interesses de elites se sobrepõe às das classes desvalidas, arrastando-as para as zonas periféricas.

Estas observações, principalmente as duas últimas, evidenciam que o conteúdo didático foi muito bem assimilado, pois demonstra a capacidade de relacionar os conceitos abstratos trabalhados em sala de aula à realidade concreta. Dito de outro, trata-se de analisar o documentário "Derrubaram o Pinheirinho" sob um olhar geográfico.

Já no tocante à ideia de "autoconstrução", muitos discentes conseguiram observar essa prática no documentário assistido e, inclusive, citaram exemplos de moradias assim construídas por parentes, amigos, vizinhos e até por eles mesmos.

O interesse pelo documentário exibido e debatido na aula de Geografia foi tão significativo que alguns alunos, curiosos sobre como estaria o terreno onde se localizava a comunidade do Pinheirinho após a expulsão dos moradores, realizaram pesquisas em sites de busca e constataram que o empresário Naji Nahas não havia vendido a sua propriedade ou tampouco promovido algum tipo de uso residencial, industrial ou agrícola. Ou seja, continuava sendo objeto de especulação imobiliária. Sendo assim, em junho de 2017, o terreno foi novamente ocupado por famílias de movimentos sem teto (MEON, 2017).

Em suma, levando-se em conta que o principal desafio da Geografia Escolar é transformar o saber acadêmico em objeto de ensino, sem desfigurá-lo, simplificá-lo ou desvalorizá-lo, mas, ao mesmo tempo, reconstruindo este saber em bases parcialmente diferentes, adaptando-o à capacidade mental dos alunos (SIMIELLI, 2007), podemos afirmar que o principal objetivo da atividade pedagógica abordada neste artigo foi alcançado, pois, após a exibição do documentário "Derrubaram o Pinheirinho", os discentes puderem ter uma melhor compreensão acerca dos conceitos de "especulação imobiliária", "gentrificação", "autoconstrução" e "segregação socioespacial", fator essencial para analisar a produção do espaço urbano.

\section{CONSIDERAÇÕES FINAIS}

A incorporação de diferentes tipos de materiais midiáticos em sala de aula é importante não apenas para aproximar o conteúdo didático da realidade dos alunos, mas, sobretudo, os incentiva a observar aspectos geográficos presentes nos conteúdos distribuídos pelos meios de comunicação de massa, desde aqueles realizados de modo independente (como é o caso do documentário "Derrubaram o Pinheirinho) até as 
produções presentes na grandes mídia.

Em relação ao estudo de caso investigado por este trabalho, podemos afirmar que as questões levantadas em "Derrubaram o Pinheirinho" não apenas permitiram que os alunos melhor assimilassem o conteúdo ministrado nas aulas de Geografia, mas também foram importantes para que eles refletissem sobre as desigualdades presentes em sociedades que adotam 0 modo capitalista de produção, questão fundamental para o pleno exercício da cidadania.

O contato com o documentário produzido por Fabiano Amorim despertou variados sentimentos nos alunos, como a indignação por causas das ações arbitrárias das forças repressivas do Estado, a repulsa aos grandes meios de comunicação de massa, pelas diferentes formas de manipulação da realidade, e a alteridade gerada pela sensibilização com os dramas vividos pelas famílias do Pinheirinho.

Portanto, consideramos que esta experiência didática com o uso de documentário, devido ao seu considerável êxito, é passível de ser replicada em outras turmas, tanto de PROEJA, quanto do designado "ensino regular".

Por outro lado, é importante frisar que o material midiático não deve ser introduzido nas aulas de Geografia como se estivesse pronto e acabado ou tampouco o professor deve transferir para este recurso paradidático a tarefa de ensinar. Agindo dessa maneira, o docente pode levar o aluno a acreditar que o conteúdo vinculado por um determinado veículo de comunicação, por si só, possui legitimidade como portador do conhecimento.

Consequentemente, somente a partir da mediação do professor, as produções midiáticas podem se constituir em suportes didáticos para o processo de ensino-aprendizagem em Geografia.

Em outros termos, isso significa que apenas o recurso tecnológico não garante a inovação didática, pois seu êxito depende intrinsecamente de um projeto pedagógico que seja bem arquitetado e conduzido pelo professor.

\section{REFERÊNCIAS}

ABRAMO, P. Padrões de manipulação na grande imprensa. 2. ed. São Paulo: Editora Fundação Perseu Abramo, 2016.

ALCÂNTARA, M. F. de. "Gentrificação". In: Enciclopédia de Antropologia. São Paulo: Universidade de São Paulo, 2018. Departamento de Antropologia. Disponível em: <http://ea.fflch.usp.br/conceito/gentrificação>. Acesso em: 30 maio 2019.

BRASIL. Constituição da República Federativa do Brasil. Brasília: Senado Federal: Centro Gráfico, 1988.

BOLAFFI, G. Habitação e urbanismo: o problema e o falso problema. In: MARICATO, E. A produção capitalista da casa (e da cidade) no Brasil industrial. v. 1, 2 ed. Alfa-ômega: São Paulo, 1979. 
COSTA, A. P. Ensino de geografia e mídia: relato de uma experiência em sala de aula. In: KATUTA, Â. M. et al. (orgs.). Geografia e mídia impressa. Londrina: Moriá, 2009.

DERRUBARAM O PINHEIRINHO. Direção de Fabiano Amorim. Brasil, 2013. Disponível em: <https://www.youtube.com/watch?v=-OqKwup0b8c>. Acesso em 29 maio 2019.

GLASS, R. Aspects of change, Londres, MacGibbon \& Kee, 1964.

GIL, A. C. Como elaborar projetos de pesquisa. São Paulo: Atlas, 1988.

GODOY, A. S. Introdução à pesquisa qualitativa e suas possibilidades. RAE Revista de Administração de Empresas, São Paulo, v. 35, n. 2, p. 57-63, 1995.

GRANT, B., What is Gentrification?, PBS Premiere: 17 june 2003. Disponível em: <http://archive.pov.org/flagwars/what-is-gentrification/ >. Acesso em: 30 maio 2019.

KATUTA, Â. M. Ensino de Geografia: conceitos, linguagens e mídia impressa. In:_, et al. (orgs). (Geo)grafando o território: a mídia impressa no ensino da Geografia. São Paulo. Expressão Popular, 2009.

LADEIRA, F. F.; LEÃO, V. de P. A influência dos discursos geopolíticos da mídia no ensino de Geografia: práticas pedagógicas e imaginários discentes. Curitiba: CRV, 2018.

LEFEBVRE, H. O direito à cidade. São Paulo: Editora Moraes, 1991.

LÜDKE, M. ANDRÉ, M. E. D. A. Pesquisa em educação: abordagens qualitativas. São Paulo: EPU, 2003.

MARICATO, E. Autoconstrução, a arquitetura possível. In: (org.). A produção capitalista da casa (e da cidade) no Brasil industrial. v. 1, 2 ed. Alfa-ômega: São Paulo, 1979.

MARQUES, Denise Leite. Importância do cinema como ferramenta de ensino. In: Caderno de Resumos III Encontro de Prática de Ensino de Geografia e Estágio Supervisionado I Encontro de Educação e Risco Ambiental do Campo das Vertentes, São João del-Rei, 2017.

MEON. Famílias voltam a ocupar área do antigo Pinheirinho em São José, Região, São José dos Campos, 3 de junho de 2017. Disponível em: <http://www.meon.com.br/noticias/regiao/familias-voltam-a-ocupar-area-doantigo-pinheirinho-em-sao-jose >. Acesso em: 31 maio 2019.

PINTO, L. T. C.; ZANARDINI, I. M. O PROEJA (Programa Nacional de Integração da Educação Profissional com a Educação de Jovens e Adultos): Reflexões a respeito da categoria trabalho como princípio educativo. XI 
Jornada do HISTEDBR - A Pedagogia Histórico-Critica, a educação brasileira e os desafios de sua institucionalização, Campinas, 2013.

REID, L. W.; ADELMAN, R. M., The Double-edged Sword of Gentrification in Atlanta, American Sociological Association, Georgia State University, apr. 2003. Disponível em:

<https://www.asanet.org/sites/default/files/savvy/footnotes/apr03/indexthree.ht $\mathrm{ml}$. Acesso em: 30 maio 2019.

ROMERO, M. et al. Indicadores de sustentabilidade dos espaços públicos urbanos: aspectos metodológicos e atributos das estruturas urbanas. XI Encontro Nacional da Associação Nacional de Pós-Graduação e Pesquisa em Planejamento Urbano e Regional. Salvador, 2005.

SCOPEL, E. G. et al. Tecendo reflexões sobre as percepções, as vivências e os saberes dos sujeitos da EJA: contribuições da reunião intermediária na formação humana e profissional de alunos e de professores do Proeja. In: OLIVEIRA, E. C. de; PINTO, A. H.; FERREIRA, M. J. de R. F. (orgs.). EJA e Educação Profissional: desafios da pesquisa e da formação no Proeja. Brasília: Liber, p. 143-166, 2012.

SIMIELLI, M. E. R. O mapa como meio de comunicação e a alfabetização cartográfica. In: ALMAIDA, R. D. de. (Org.). Cartografia Escolar. São Paulo: Contexto, 2007. 